\title{
Barriers to Online Learning during COVID-19 Pandemic: Students' Perspective
}

\author{
Mohd Shakir
}

Assistant Professor, Department of Education, Aligarh Muslim University, Aligarh, India

Corresponding author: aligarhshakir@gmail.com

Received: $15-10-2021$

Revised: 03-12-2021

Accepted: $17-12-2021$

\begin{abstract}
Prior to the upsurge of COVID-19 pandemic, the online teaching-learning resources were considered as additional e-learning aids that could enrich the teaching-learning experiences of the students as well as of teachers. However, the outbreak of COVID-19 pandemic has made online mode of teaching-learning an indispensable unit of education system. Globally the academic community has adopted online mode of learning for ensuring continued educational services during COVID-19. Despite numerous possibilities offered by online mode, the adoption of this method was not much smooth as many of the educational stakeholders were not much prepared for intricacies of the process due to which they faced many unforeseen challenges. In the light of the above changes witnessed by education system during COVID-19 pandemic, this paper predominantly highlights the challenges faced by students in continuing and acquiring education through online mode of teaching-learning. The challenges discussed in the present paper consider online teaching-learning process as a temporary solution instead of a substitute to conventional classroom scenario. Furthermore, considering online learning solutions as an indispensable and irreplaceable unit of the present teaching-learning scenario, the present paper is an effort to put forward some suggestions for overcoming the barriers to online mode of teaching- learning.
\end{abstract}

Keywords: Online learning, digital literacy, adaptability, miniscule interaction, digital eye strain, and COVID-19

The sudden outbreak of COVID-19 has resulted in unprecedented humanitarian crisis. The disease caused by corona virus has made global impacts and disrupted the normal functioning of almost every sector with education being one of them (Dhawan, 2020). During this existential crisis, the technology based online learning emerged as the only viable alternative for ensuring the continuity in teaching-learning process. In the pre-covid phase the technology based virtual learning, use of e-learning resources, virtual platforms were considered as the options to complement and facilitate the conventional teaching-learning process, however since the advent of the deadly virus, the use of e-learning resources and virtual platforms became vital for continuing education. It may be said that during COVID-19 induced lockdowns dependency on online teaching resources and use of online learning platforms has potentially increased. Consequently, almost every educational institution adopted online mode of learning as a means of ensuring continuity in teaching-learning process.

Advantages of Online Teaching-Learning: To begin with the advantages of online teachinglearning it must be mentioned that online mode of teaching-learning offers various benefits in terms of convenience, flexibility and affordability (Dhawan, 2020). Online learning is eco-friendly in nature and provides wide range of learning opportunities for

How to cite this article: Shakir, M. (2021). Barriers to Online Learning during COVID-19 Pandemic: Students' Perspective. Educational Quest: An Int. J. Edu. Appl. Soc. Sci., 12(03): 239-244.

Source of Support: None; Conflict of Interest: None (C) 
various learners. Additionally, online learning can offer personalized learning solutions that could cater to the learning needs of different learners. The accessibility to learning material has also been made easy through online learning approach. The lectures can be recorded, archived and shared, thus providing students easy accessibility to the course material and allowing self-paced learning. Furthermore, in online learning various innovative pedagogical strategies can be utilised for making teaching-learning more interesting and student friendly. Online learning may also provide meaningful student-teacher interaction through live chat/messages in online classrooms; also, the immediate feedback on work has been made possible through online mode of learning. Shenoy et al. (2020) reported that student's participation is better in virtual class than in regular offline classrooms.

Integration of technology in the educational process has been a challenging task for teachers as well as for learners. The sudden shift from traditional face to face teaching-learning model to technology based virtual learning has posed certain challenges for teachers as well as learners. The sudden shift from offline to online teaching has increased stress and workload for teachers (Rapanta et al. 2020). Although integration of Information and communication technology into education provides numerous possibilities and opportunities for teachers and learners such as self-paced learning, accessibility to wide range of courses and learning materials etc however, the effective use of ICT in education requires certain level of technical knowledge and skills, which probably became challenges in online mode of learning (Mahyoob, 2020). Subedi et al. (2020) concluded that students suffered interruptions during online lessons due to internet and electricity issues, and students were also faced problems in limited data packs for their online lessons. Parkes et al. (2015) referred today's learners as a 'digital natives' in reflection of their apparent ease and familiarity with digital technology.

It is also observed that during pre COVID-19 some teachers especially the senior teachers were quite resistant towards technology adoption (McQuiggan, 2007), however during COVID-19 period most of the teachers including seniors gradually became receptive to technology based virtual mode of teaching-learning. It may be said that COVID-19 has become catalyst for technology adoption as many teachers have adopted virtual mode of teachinglearning and they have positive experiences (Shenoy et al. 2020).

\section{Objectives}

1. To study the barriers to online teachinglearning faced by students during COVID-19 pandemic.

2. To give plausible suggestions for managing the barriers to online teaching-learning faced by students during COVID-19 pandemic.

\section{Methodology}

For the present study, a comprehensive literature survey was conducted through secondary sources such as, research papers, articles, e-newspapers, e-books and different websites. Survey was conducted in Aligarh Muslim University in the online mode. The researcher asked students to submit in writing the major barriers faced by them during online teaching-learning. The survey is inclusive of 279 students who responded with regard to the major barriers they face during online teaching-learning process. This research paper, therefore; predominantly centers itself around the major fallouts of online teaching teaching-learning process, keeping in purview the perspectives of students.

The below mentioned list hence elucidates upon the major barriers faced by students during online teaching-learning in the new normal situation on account of COVID-19:

\section{Barriers in online mode of teaching- learning: Student's perspective}

1. Adaptability issue: It has been observed that initially there was little readiness among students to adopt online mode of teaching-learning. Switching over to completely technology based virtual learning from long existing traditional mode of learning was a challenge for students as well as for teachers. The probable reasons behind the non receptive behaviour of some students may be lack of technical knowledge; unavailability of smart devices, no wifi connections or limited internet data packs, some devices may have not supported 
the applications and softwares required for online classes, issues of technostress etc.

2. Inability to attend lectures regularly: Students have missed out a lot on their lectures during the pandemic comparatively. Earlier when they used to attend offline classes in the Department of Education, they were more focused, enthusiastic and regular. The conventional classrooms provided them an environment beyond teaching-learning that facilitated their intellect to grow beyond the textbooks but in online set up, the mere completion of course is a humongous task in itself. Due to this lacuna, regularity in lectures is solely dependent on intrinsic motivation of a student.

3. Miniscule Interaction: Students feel that they have limited time to discuss things in the classes resulting which their interaction pertaining to their comprehension gaps has been minimized extensively.

\section{Inaccessibility of writings/works by great} scholars: Students are not able to access libraries and others facilities provided by the institution. 'The lack of books, works, and writings by great scholars will surely affect our research work in the coming semesters'; reported one student.

5. Low Self Motivation: It may be said that shifting from long existing traditional mode of learning to online learning platforms has been a challenge for students. When students find online learning to be complex, they tend to lose their motivation. In online mode of learning staying motivated and completing a task with full enthusiasm is a challenge for students.

6. Lack of Social Interaction: Effective and meaningful teacher-pupil interactions may be considered as an indicator of healthy classroom environment however in online classes effective social interaction is a missing factor. The pandemic has made us realize that school is not just a place for learning but also a facilitator of healthy social interaction. Due to lack of social interaction many students may feel a sense of isolation and they tend to lose interest in online classes.

7. Technical Issue: In a developing country like India many students are not well equipped with basic technical requirements such as a stable internet connection, smart devices, uninterrupted electricity which may be considered as prerequisites for online learning (Subedi et al. 2020). Due to this, it becomes difficult for students to participate actively or even attend online classes. Students may also face various technical glitches in virtual classes or other platforms that requires high speed internet connection.

8. Inability to manage time: It is observed that some students find it difficult to manage time and other academic activities in online classes. They are novice in the field of online learning and require intensive assistance in order to maintain their continuity efficiently. Systematically planned curriculum and online practice sessions related to various classroom activities are needed to enable students manage time effectively in online classes.

9. Inability in comprehension of practical subjects: Subjects like school internships lose their actual value when they are not practiced in actual classroom environment. Hence, the entire understanding of subject depends upon mere observations that students had during school days and imagination henceforth.

10. Digital Eye strain: Studying on screen led to a lot of health issues, like lethargy, watery eye, week eye sight, headache and migraine etc.

11. Household chores: "I mean nobody cares that I am attending the class on phone, if I am at home, it could not be a class on phone" wrote one female student.

12. Lack of seriousness: When we attend classes offline, we plan prior and attend lectures accordingly however, online mode has ruined that serious outlook towards life up to some extent because at the end, our home is a comfortable place and "Comfort zone is a place where nothing grows".

13. Informality persists: Acquisition of education is a very serious task and hence in order to facilitate this task in most effective way possible, many educationists favored the set up of formal environment through schools, universities etc. Online set up has subtracted that formality out of the teaching-learning process because easy distractions through background noises are always there.

14. Low on affordability: Class timing is from 8:00 am to 2:00 pm which requires lots of data, this results in frequent purchase of net packs (Subedi et al. 2020), in spite of these material sufficiency, the 
education process is quite compromising; hence these classes are low on affordability as well as cost benefit ratio

15. Know how: Most of the students do not know how to use zoom app, Google meet, and other platforms.

16. Lack of transparency in evaluation process: Since the examination process in online exams is mostly telephonic, therefore sometimes teachers inadvertently presume that the student is not being transparent in delivery of his answers specially when there is prolonged silence after the questions. This prolonged silence is misconstrued as cheating which is sometimes due to nervousness or contemplation upon question. Such preconceived notions of teacher about students result in lack of transparency of evaluation.

17. Prolonged hours of waiting: This becomes problematic to those students who have end roll numbers. They have to wait for long duration for viva call and their energy level and enthusiasm becomes low and teachers after calling substantial amount of roll numbers become exhausted and are not enthusiastic towards these roll numbers which results in loss of students, zeal too.

18. Class or a monologue: In online classes generally, teachers do not turn their video on and similar is the attitude of students. This also makes the classroom environment least interactive and hence it seems that the teacher is giving a monologue on a topic which really is not that effective in giving us conceptual clarity.

19. Indiscipline: The online set up has internalized the indiscipline in students as their schedule has completely been distorted. "Early to bed, early to rise makes a man healthy, wealthy and wise" seems an unachievable goal in this environment.

20. Increment in virtual screen timing instigates depression: Sitting all day long on a computer screen makes one feel hyper and to concentrate on for prolonged hours leads to dark depression. Virtually learning makes you hyper and then ultimately to depression.

21. No non-verbal Communication: Non verbal communication is one of the most important aspects of teaching because it enables the learner to understand the unsaid words and to comprehend between the lines. This also enhances the verbal communication. Also, verbal communication in itself is not absolute hence, the role of body language, facial expressions and gestures communicate a concept in its true sense but when we miss out on it, we certainly miss the holistic understanding of the content.

22. Digital distracters: The learning from home through virtual mode has created a culture of distraction. At home students are surrounded by various entertainment devices which create a distracting environment (Brown, 2021). It is also observed that many students take online classes on their smart phones on which students keep receiving notifications from various social media applications; this in turn may distract students in online classes.

\section{Suggestions in the light of above discussed Issues}

1. Prepare students to adapt changes: The technical perspective of students may be addressed at the initial stage of online learning. Students having a traditional mindset must be encouraged and prepared to accept the change with open heart and mind. Further support for technical issues should be given so that the learners do not get discouraged due to technical glitches.

2. Adjustability is the key: In extraordinary situations, in situations that pose the danger of lives in maintenance of normalcy, it is important to adjust in the circumstance and compromise for the time being. Raman, \& Yamat, (2014) suggested that teachers should develop classroom management skills so as to regulate and involve the students in their lessons. They should also learn and acquire some innovative ways of integrating ICT to reinforce teaching and learning process.

3. Provision of doubt sessions: In order to eradicate the boundation of time limit and lacunae in concept clarity the teacher can schedule doubt sessions after the completion of classes

4 Accessibility to digital library: The universities should digitalize their libraries and should give access to its students of the same

5. Know your purpose: In order to motivate to study in cumbersome circumstances, it is important for an individual to know as to why does he/she want to acquire education and the answer that he/ 
she receives would act as a catalyst to his faded motivation

6. Online social collaborations: Just as in offline set ups, students do have a lunch break or zero periods which facilitate their intermingling, in similar fashion, the students can schedule their online meetups on various platforms like Google meet and can at least minimise the feeling of seclusion.

7. Broadband connection- a viable option: The students often have limited data packs that have set provision of data limit and comparatively less speed, however, broadband connections are much more secure in terms of speed and financially cheaper as well. Further a study done by Mahmood (2020) suggests that teachers should not be too strict and should show flexibility and should give extra time to students.

8. Scheduled Planning: In order to manage time, the intensive planning is required. For instance, even in schools the time is managed for every subject with time tables similarly students can adopt planning techniques in order to schedule their time efficiently.

9. Supplementation of practical knowledge: Supplementation of practical knowledge with the help of You Tube videos can fill in the gaps in the understanding. Further, the administration should try to equip itself for the solutions of such problems.

10. Anti-glare glasses: In order to minimise digital eyestrain, the students can use the anti-glare glasses for their online learning. Also, they can reduce their screen time by adopting viable alternatives for their enjoyments.

11. Leniency: Allow some leniency to students who have additional responsibilities at home. They may be given additional time to complete their tasks. Alternative learning activities must be provided if they are unable to attend synchronous sessions. Baticulon et al. (2021).

12. Development of awareness among students: In order to adjust to this situation, the awareness must be developed among parents so that they take the classes of their children very seriously.

13. Host Centric Permissibility option: In order to eradicate informality out of classroom environment, the teachers should adopt the method of host centric permissibility whereby the student can unmute himself/herself during the class only when the teacher permits him to do so mechanically.

14. Assigned scholarships for data pack: The University can separate the data of economically weaker students and facilitate them with data pack scholarships so that they can continue their learning in a proper manner.

15. Workshop for application understandability: The workshops can be arranged for students who are unable to understand the functioning of applications like zoom, Google meet so that they know how to use them

16. Video graphic viva is a viable option: In order to maintain the transparency of evaluation the teacher can switch to viva voce with a video on so that both the teacher and students remain satisfied with the evaluation

17. Division of roll numbers among teachers: In such cases the teachers can divide equal number of students among themselves minimises the prolonged hours of waiting.

18. Teachers' camera: Teachers may turn their video on for better interaction among students: and should open the room for dialogue by keeping the last minutes of class for discussion and interaction

19. Face the challenge: Maintaining discipline in such unforeseen circumstances can be a challenge but students should challenge themselves and go beyond the limits of obstacles because "winners do not do different things, they do things differently" (Shiv Khera, 2007).

20. Find alternatives for entertainment: Since education is an important part and parcel of life, hence; the devoted time cannot be cut short, however the screen time of students when they are exposed to mobile for entertainment purposes can be reduced and they can switch to read fictional books, indoor games instead

21. Use of Verbal reinforcers and emojis: The nonverbal communication do play an important role but online set up comes with its own limitations, however this set up can be utilised in its best capacity by communicating the emotions through verbal reinforcers and emojis as well. Also, when teacher turns his video on the facial expressions and hand gestures are sufficient to communicate the real essence of his unsaid words.

22. Foster engagement through innovative 
pedagogy: Innovative pedagogical strategies such as online collaborative learning, flipped classroom learning, personalized learning etc has been associated with increasing learner's motivation, engagement and critical thinking (Harasim, 2012; Cheta and Augustein, 2015; Zhang, 2020). Thus, learning through advanced pedagogy may help in enhanced intensity to learn, better concentration, retention, active participation and improved performance (Malhotra and Malhotra, 2021).

\section{CONCLUSION}

The online teaching-learning process poses enormous challenges among students. It not only affects their intellect in terms of domain knowledge but also takes them to the platform of being a passive listener and performer in real life scenario. However, it should also be taken into consideration, that the students must be acquainted to deal with such challenges in life and find better alternatives to face the circumstance. This requires co-operation of both students, teachers along with institutional administration. Cultivating the habit of making best out of all situations is the key to strive towards excellence in limited resources.

\section{REFERENCES}

Baticulon et al. 2021. Barriers to Online Learning in the Time of COVID-19: A National Survey of Medical Students in the Philippines, Medical Science Educator, 31: 615-626.

Brown, W.S. 2021. Successful strategies to engage students in a COVID-19 environment. Frontiers in Communication, 6.

Cheta, W. and Augustein, S.E. 2015. Collaborative learning in a virtual classroom: Its status in the current digital era, European Journal of Research and Reflection in Educational Sciences, 3(5): 45-51.

Dhavan, S. 2020. Online learning: a panacea in the time of covid-19 crisis, Journal of Educational Technology Systems, 49(1): 5-22.

Harasim, L. 2012. Learning Theory and Online
Technologies New York/London: Routledge.

Mahmood, S. 2020. Instructional strategies for online teaching in COVID-19 pandemic. Human Behavior and Emerging Technologies, 3: 199-203.

Mahyoob, M. 2020. Challenges of e-learning during the COVID-19 pandemic experienced by EFL learners. Arab World English Journal, 11(4): 351-362.

Malhotra, M. and Malhotra, T. 2021. Innovation in learning environment: A new perspective of learning in digital era, Scholarly Research Journal for Humanity Science E English Language, 9(43): 10828-10835

McQuiggan, C.A. 2007. The role of faculty development in online teaching's potential to question teaching beliefs and assumptions. Online Journal of Distance Learning Administration, 10(3): 1-13.

Parkes, M., Stein, S. and Reading, C. 2015. Student preparedness for university e-learning environments. The Internet and Higher Education, 25: 1-10.

Raman, K. and Yamat, H. 2014. Barriers Teachers Face in Integrating ICT During English Lessons: A Case Study, The Malaysian Online Journal of Educational Technology, 2(3): 11-19.

Rapanta., C., Botturi., L., Goodyear, P., Guàrdia, L. and Koole, M. 2020. Online university teaching during and after the covid-19 crisis: refocusing teacher presence and learning activity, Post digital Science and Education, 2: 923-945.

Shenoy, V., Mahendra, S. and Vijay, N. 2020. COVID-19 Lockdown: Technology Adaptation, Teaching, Learning, Students Engagement and Faculty Experience, Mukt Shabd Journal, 9(4): 698-702.

Subedi, S., Nayaju, S., Subedi, S., Shah, S.K. and Shah, J.M. 2020. Impact of E-learning during COVID-19 pandemic among nursing students and teachers of Nepal, International Journal of Science and Healthcare Research, 5(3): 68-76.

Zhang, A. et al. 2020. Effects of Traditional and Innovative Teaching Methods on Technical College Student's Achievement in Computer Craft Practices, SAGE Open, October-December, pp. 1-11. 